九州大学学術情報リポジトリ

Kyushu University Institutional Repository

\title{
Complex Representatioin of Field-Forage- Ruminant Relationships using Symmetric Properties of Euler's Formula
}

Shimojo, Masataka

Laboratory of Animal Feed Science, Division of Animal Science, Department of Animal and Marine Bioresoruce Sciences, Faculty of Agriculture, Kyushu University

Ikeda, Kentaro

Research Fellow, Faculty of Agriculture, Kyushu University

Asano, Yoki

Research Fellow, Faculty of Agriculture, Kyushu University

Ishiwaka, Reiko

他

https://doi.org/10.5109/4507

出版情報：九州大学大学院農学研究院紀要. 47 (2)，pp.367-372，2003-02-01. Faculty of Agriculture, Kyushu University

バージョン :

権利関係 : 


\title{
Complex Representation of Field-Forage-Ruminant Relationships using Symmetric Properties of Euler's Formula
}

\section{Masataka SHIMOJO ${ }^{\dagger}$, Yoki ASANO ${ }^{1)}$, Kentaro IKEDA ${ }^{1)}$, Reiko ISHIWAKA ${ }^{2}$, Tao SHAO ${ }^{3)}$, Hiroyuki SATO ${ }^{1)}$, Manabu TOBISA, Yutaka NAKANO', Noriko OHBA $^{5)}$, Yasukatsu YANO ${ }^{6)}$ and Yasuhisa MASUDA}

\author{
Laboratory of Animal Feed Science, Division of Animal Science, Department of \\ Animal and Marine Bioresource Sciences, Faculty of Agriculture, \\ Kyushu University, Fukuoka 812-8581, Japan \\ (Received October 31, 2002 and accepted November 7, 2002)
}

\begin{abstract}
This study suggests that the complex representation of field-forage-ruminant relationships for the nutrient cycling has a relation to symmetric properties of Euler's formula with respect to its differentiation giving a series of derivatives and $\pi / 2$ rotations.
\end{abstract}

\section{INTRODUCTION}

In the preceding report (Shimojo et al., 2003) in this issue, we have tried to give a symbolic representation of field-forage-ruminant relationships using rotations, on the complex plane, of polar coordinates describing digestible and indigestible dry matter of forages connected with fields. It is known that the polar representation on the complex plane is closely related to Euler's formula.

The present study was designed to relate the complex representation of field-forage -ruminant relationships to symmetric properties of Euler's formula.

\section{DIFFERENTIATION-ROTATION RELATIONSHIPS IN EULER'S FORMULA}

\section{Euler's formula}

Euler's formula is given by

$$
\exp (\boldsymbol{i} \theta)=\cos \theta+\boldsymbol{i} \sin \theta
$$

where $\boldsymbol{i}$ =imaginary unit, $\theta=$ real variable.

1) Laboratory of Animal Feed Science, Division of Animal Science, Department of Animal and Marine Bioresource Sciences, Graduate School of Bioresource and Bioenvironmental Sciences, Kyushu University

2) Research Fellow of the Japan Society for the Promotion of Science

3) Visiting Research Scientist from the People's Republic of China

4) Kyushu University Farm, Fukuoka $811-2307$

5) Research Student, School of Agriculture, Kyushu University

6) Technical Specialist, School of Agriculture, Kyushu University

. Corresponding Author (E-mail: mshimojo@agr.kyushu-u.ac.jp) 


\section{Differentiation of $\exp (i \theta)$} by

The differentiation of $\exp (\boldsymbol{i} \theta)$ with respect to $\theta$ using its MacLaurin's series is given

$$
\begin{aligned}
\frac{d}{d \theta}\{\exp (\boldsymbol{i} \theta)\} & =\frac{d}{d \theta}\left(1+\frac{\boldsymbol{i} \theta}{1 !}+\frac{\boldsymbol{i}^{2} \theta^{2}}{2 !}+\cdots \cdots+\frac{\boldsymbol{i}^{n} \theta^{n}}{n !}+\cdots \cdots\right) \\
& =\boldsymbol{i}+\frac{\boldsymbol{i}^{2} \theta}{1 !}+\frac{\boldsymbol{i}^{3} \theta^{2}}{2 !}+\cdots \cdots \frac{\boldsymbol{i}^{n+1} \theta^{n}}{n !}+\cdots \cdots \\
& =\boldsymbol{i}\left(1+\frac{\boldsymbol{i} \theta}{1 !}+\frac{\boldsymbol{i}^{2} \theta^{2}}{2 !}+\cdots \cdots \frac{\boldsymbol{i}^{n} \theta^{n}}{n !}+\cdots \cdots\right) \\
& =\boldsymbol{i} \cdot \exp (\boldsymbol{i} \theta)
\end{aligned}
$$

where $\boldsymbol{i} \cdot \exp (\boldsymbol{i} \theta)$ results from keeping the form of $\exp (\boldsymbol{i} \theta)$ itself invariant when differentiated with respect to $\theta$.

Combining (1) and (2) gives

$$
\begin{aligned}
\frac{d}{d \theta}\{\exp (\boldsymbol{i} \theta)\} & =\boldsymbol{i} \cdot \exp (\boldsymbol{i} \theta) \\
& =\boldsymbol{i} \cdot(\cos \theta+\boldsymbol{i} \sin \theta)
\end{aligned}
$$

It is shown in (3) that the differentiation of $\exp (\boldsymbol{i} \theta)$ with respect to $\theta$ gives $\pi / 2$ rotation ( $\pi / 2$ anticlockwise rotation) of $\cos \theta+i \sin \theta$. In other words, $\pi / 2$ rotation results from keeping the form of $\exp (\boldsymbol{i} \theta)$ itself invariant when differentiated with respect to $\theta$. Thus,

$$
\begin{aligned}
\frac{d}{d \theta}(\cos \theta+\boldsymbol{i} \sin \theta) & =\boldsymbol{i} \cdot(\cos \theta+\boldsymbol{i} \sin \theta) \\
& =\left(\cos \frac{\pi}{2}+\boldsymbol{i} \sin \frac{\pi}{2}\right) \cdot(\cos \theta+\boldsymbol{i} \sin \theta) \\
& =\cos \left(\frac{\pi}{2}+\theta\right)+\boldsymbol{i} \sin \left(\frac{\pi}{2}+\theta\right) \\
& =-\sin \theta+\boldsymbol{i} \cos \theta
\end{aligned}
$$

This shows that $-\sin \theta+\boldsymbol{i} \cos \theta$ results from keeping the invariance in the relative position to the two axes when $\cos \theta+\boldsymbol{i} \sin \theta$ is differentiated with respect to $\theta$. It is also shown in (4) that, by $-\pi / 2$ parallel movement, $\cos \theta$ and $\sin \theta$ are superposed on $-\sin \theta$ and $\cos \theta$, respectively.

Then, the following two derivatives and rotations are given.

$$
\begin{aligned}
\frac{d^{2}}{d \theta^{2}}\{\exp (\boldsymbol{i} \theta)\} & =\boldsymbol{i}^{2} \cdot \exp (\boldsymbol{i} \theta) \\
& =\boldsymbol{i}^{2} \cdot(\cos \theta+\boldsymbol{i} \sin \theta) . \\
\frac{d^{3}}{d \theta^{3}}\{\exp (\boldsymbol{i} \theta)\} & =\boldsymbol{i}^{\mathbf{3}} \cdot \exp (\boldsymbol{i} \theta) \\
& =\boldsymbol{i}^{3} \cdot(\cos \theta+\boldsymbol{i} \sin \theta) .
\end{aligned}
$$


COMPLEX REPRESENTATION OF FIELD-FORAGE-RUMINANT RELATIONSHIPS

Polar representation on the complex plane of digestible dry matter $(D)$ and indigestible dry matter $(I)$ of the forage mass $(W)$ connected with the field

As shown in the preceding report (Shimojo et al., 2003) in this issue,

$$
\begin{aligned}
Z_{\mathbf{1}} & =D+\boldsymbol{i} I \\
& =r(\cos \theta+\boldsymbol{i} \sin \theta),
\end{aligned}
$$

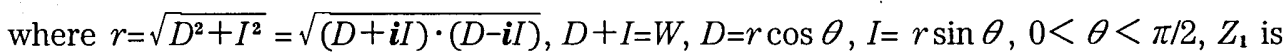
regarded as the field with standing forage composed of $D$ and $I$ (both $D$ and $I$ are considered to be visible).

$$
\begin{aligned}
Z_{\mathbf{1}} \cdot \boldsymbol{i} & =r(\cos \theta+\boldsymbol{i} \sin \theta) \cdot \boldsymbol{i} \\
& =r(-\sin \theta+\boldsymbol{i} \cos \theta)
\end{aligned}
$$

where $-r \sin \theta=-I, r \cos \theta=D, Z_{1} \cdot \boldsymbol{i}$ is associated with the ruminant production from digestible nutrients of forages ( $D$ is visible but $-I$ is considered to be invisible).

$$
\begin{aligned}
Z_{\mathbf{1}} \cdot \boldsymbol{i}^{2} & =r(\cos \theta+\boldsymbol{i} \sin \theta) \cdot \boldsymbol{i}^{2} \\
& =r(-\cos \theta-\boldsymbol{i} \sin \theta)
\end{aligned}
$$

where $-r \cos \theta=-D,-r \sin \theta=-I, Z_{1} \cdot \boldsymbol{i}^{2}$ is regarded as the field without standing forage (both $-D$ and $-I$ are invisible).

$$
\begin{aligned}
Z_{1} \cdot \boldsymbol{i}^{3} & =r(\cos \theta+\boldsymbol{i} \sin \theta) \cdot \boldsymbol{i}^{3} \\
& =r(\sin \theta-\boldsymbol{i} \cos \theta)
\end{aligned}
$$

where $r \sin \theta=I,-r \cos \theta=-D, Z_{\mathbf{1}} \cdot \boldsymbol{i}^{3}$ is associated with feces excreted from ruminants ( $I$ is visible but $-D$ is invisible).

FIELD-FORAGE-RUMINANT RELATIONSHIPS AND EULER'S FORMULA

Correspondences between (1) and (7), between (3) and (8), between (5) and (10), and between (6) and (12)

$$
\begin{aligned}
& \exp (\boldsymbol{i} \theta)=\cos \theta+\boldsymbol{i} \sin \theta \\
& Z_{1}=r(\cos \theta+\boldsymbol{i} \sin \theta)
\end{aligned}
$$




$$
\begin{aligned}
& \frac{d}{d \theta}\{\exp (\boldsymbol{i} \dot{\theta})\}=\boldsymbol{i} \cdot \exp (\boldsymbol{i} \theta) \\
& =(\cos \theta+\boldsymbol{i} \sin \theta) \cdot \boldsymbol{i} \\
& Z_{\mathbf{1}} \cdot \boldsymbol{i}=r(\cos \theta+\boldsymbol{i} \sin \theta) \cdot \boldsymbol{i} . \\
& \frac{d^{2}}{d \theta^{2}}\{\exp (\boldsymbol{i} \theta)\}=\boldsymbol{i}^{2} \cdot \exp (\boldsymbol{i} \theta) \\
& =(\cos \theta+\boldsymbol{i} \sin \theta) \cdot \boldsymbol{i}^{2}, \\
& Z_{1} \cdot \boldsymbol{i}^{2}=r(\cos \theta+\boldsymbol{i} \sin \theta) \cdot \boldsymbol{i}^{2} . \\
& \frac{d^{3}}{d \theta^{3}}\{\exp (\boldsymbol{i} \theta)\}=\boldsymbol{i}^{\mathbf{3}} \cdot \exp (\boldsymbol{i} \theta) \\
& =(\cos \theta+\boldsymbol{i} \sin \theta) \cdot \boldsymbol{i}^{3}, \\
& Z_{1} \cdot \boldsymbol{i}^{3}=r(\cos \theta+\boldsymbol{i} \sin \theta) \cdot \boldsymbol{i}^{3} .
\end{aligned}
$$

These four correspondences show that the complex representation of field-forage-ruminant relationships has a resemblance to the differentiation of $\exp (\boldsymbol{i} \theta)$ giving a series of derivatives and $\pi / 2$ rotations.

The exponential function with base $e$ and Euler's formula are occasionally used for describing some natural phenomena. Our previous report (Shimojo et al., 2002b) of relative growth rate (RGR) suggests that the analytic description of growth phenomena has a relation to symmetric properties of $\exp \{(\mathrm{RGR}) \cdot t$ ) itself with respect to its differentiation and definite integral. The present study suggests that the complex representation of field-forage-ruminant relationships for the nutrient cycling (Shimojo et al., 2003) is related to symmetric properties of $\exp (\boldsymbol{i} \theta)$ itself with respect to its differentiation giving a series of derivatives and $\pi / 2$ rotations. It is, therefore, suggested that the analytic description of some aspects of ruminant agriculture is given by symmetric properties of exponential functions with base $e$ including Euler's formula. This may also lead to the description of a sort of sustainability in the ruminant agriculture (Shimojo et al., 2002a, 2003).

\section{INDEFINITE INTEGRAL OF $\boldsymbol{i} \cdot \exp (\boldsymbol{i} \theta)$ AND $-\pi / 2$ ROTATION}

Let us take up the indefinite integral of $\boldsymbol{i} \cdot \exp (\boldsymbol{i} \theta)$ in (2). The indefinite integral of $\boldsymbol{i} \cdot \exp (\boldsymbol{i} \theta)$ using its MacLaurin's series is given by

$$
\begin{aligned}
\int \boldsymbol{i} \cdot \exp (\boldsymbol{i} \theta) d \theta & =\int \boldsymbol{i}\left(1+\frac{\boldsymbol{i} \theta}{1 !}+\frac{\boldsymbol{i}^{2} \theta^{2}}{2 !}+\cdots \cdots+\frac{\boldsymbol{i}^{n} \theta^{n}}{n !}+\cdots \cdots\right) d \theta \\
& =\int\left(\boldsymbol{i}+\frac{\boldsymbol{i}^{2} \theta}{1 !}+\frac{\boldsymbol{i}^{3} \theta^{2}}{2 !}+\cdots \cdots+\frac{\boldsymbol{i}^{n+1} \theta^{n}}{n !}+\cdots \cdots\right) d \theta \\
& =\left\{\left(1+\frac{\boldsymbol{i} \theta}{1 !}+\frac{\boldsymbol{i}^{2} \theta^{2}}{2 !}+\cdots \cdots+\frac{\boldsymbol{i}^{n} \theta^{n}}{n !}+\cdots \cdots\right)-1\right\}+(C+1)
\end{aligned}
$$




$$
=\exp (\boldsymbol{i} \theta)-1+(C+1)
$$

where $-1+(C+1)=C=$ integration constant:

In $(14),-1$ can be vanished, namely $-1+(C+1)=C$. It seems, however, that the indefinite integral of $\boldsymbol{i} \cdot \exp (\boldsymbol{i} \theta)$ gives a reason for remaining of -1 as one of the integration constants. If it is accepted at the risk of making mistakes, the following will be given as an example of (14),

$$
\begin{aligned}
\int \boldsymbol{i} \cdot \exp (\boldsymbol{i} \theta) d \theta & =\exp (\boldsymbol{i} \theta)-1 \\
& =(-\boldsymbol{i}) \cdot \boldsymbol{i}(\cos \theta+\boldsymbol{i} \sin \theta)-1 \\
& =(\cos \theta+\boldsymbol{i} \sin \theta)-1
\end{aligned}
$$

It is shown in (15) that the indefinite integral of $\boldsymbol{i} \cdot \exp (\boldsymbol{i} \theta)$ gives $-\pi / 2$ rotation $(\pi / 2$ clockwise rotation) of $\boldsymbol{i}(\cos \theta+\boldsymbol{i} \sin \theta)$. This occurs as if to convert the ruminant production (8) to the forage production (7), which seems to have a resemblance to the ruminant production analysis with an intersection for entering the analysis of forage production (Shimojo et al., 2002a).

If -1 in (15) is rewritten in order to adjust its form to that of $\exp (\boldsymbol{i} \theta)$ and $(\cos \theta+$ $\boldsymbol{i} \sin \theta$ ), the following equality will be used;

$$
\begin{aligned}
-1 & =\cos \{(2 n+1) \pi\}+\boldsymbol{i} \sin \{(2 n+1) \pi\} \\
& =\exp \{\boldsymbol{i}(2 n+1) \pi\},
\end{aligned}
$$

where $n=0, \pm 1, \pm 2, \pm 3$,

The special case when $n=0$ in (16) is given by

$$
\begin{aligned}
-1 & =\cos \pi+\boldsymbol{i} \sin \pi \\
& =\exp (\boldsymbol{i} \pi) .
\end{aligned}
$$

Rewriting (15) using (17) gives

$$
\exp (\boldsymbol{i} \theta)+\exp (\boldsymbol{i} \pi)=(\cos \theta+\boldsymbol{i} \sin \theta)+(\cos \pi+\boldsymbol{i} \sin \pi) .
$$

Since $\exp (\boldsymbol{i} \pi)$ shows $\pi$ rotation ( $\pi / 2$ rotation followed by $\pi / 2$ rotation), the following will be given according to the preceding report (Shimojo et al., 2003);

$Z_{1}$ (field with standing forage) $\stackrel{\times \exp (i \pi)}{\longrightarrow} Z_{1} \cdot \boldsymbol{i}^{2}$ (field without standing forage),

$Z_{1} \cdot \dot{\boldsymbol{i}}^{2}$ (field without standing forage) $\stackrel{\times \exp (i \pi)}{\longrightarrow} Z_{2}$ (field with the next standing forage),

$Z_{1} \cdot \boldsymbol{i}$ (ruminant production from digestible nutrients) $\stackrel{\times \exp (i \pi)}{\longrightarrow} Z_{1} \cdot \boldsymbol{i}^{3}$ (feces excreted 
$Z_{1} \cdot \boldsymbol{i}^{3}$ (feces) $\stackrel{\times \exp (i \pi)}{\longrightarrow} Z_{2} \cdot \boldsymbol{i}$ (ruminant production based on the next forage production). (22)

It is suggested from $(19) \sim(22)$ that describing the continuation of ruminant agriculture is also related to the rotation given by $\exp (\boldsymbol{i} \pi)$.

\section{CONCLUSIONS}

It is concluded that the complex representation, using polar coordinates, of field-forage -ruminant relationships suggesting the nutrient cycling is related to symmetric properties of Euler's formula with respect to its differentiation giving a series of derivatives and $\pi / 2$ rotations.

\section{REFERENCES}

Shimojo, M., K. Ikeda, Y. Asano, R. Ishiwaka, M. Tobisa, T. Shao, N. Ohba, H. Sato, Y. Matsufuji, Y. Yano and Y. Masuda 2002a An intersection of ruminant production and forage production. J. Fac. Agr., Kyushu Univ., 46: 321-329

Shimojo, M., Y. Asano, K. Ikeda, R. Ishiwaka, T. Shao, N. Ohba, H. Sato, Y. Matsufuji, M. Tobisa, Y. Yano and Y. Masuda 2002b Basic growth analysis and symmetric properties of exponential function with base e. J. Fac. Agr., Kyushu Univ., 47: 55-60

Shimojo, M., K. Ikeda, Y. Asano, R. Ishiwaka, T. Shao, H. Sato, M. Tobisa, Y. Nakano, N. Ohba, Y. Yano and Y. Masuda 2003 A symbolic representation of field-forage-ruminant relationships using polar form on the complex plane. J. Fac. Agr., Kyushu Univ., 47: 359-366 